\title{
O OURO EM GANA NO SÉCULO XXI: ESCALAS E ORIGENS DO CAPITAL NA MINERAÇÃO AURÍFERA
}

\author{
GOLD IN GHANA IN THE 21st CENTURY: SCALES AND \\ ORIGINS OF CAPITAL IN GOLD MINING
}

\author{
L'OR AU GHANA AU XXIE SIECLE: ECHELLES ET ORIGINES \\ DU CAPITAL DANS L'EXTRACTION DE L'OR \\ Kauê Lopes dos Santos - Universidade de São Paulo - São Paulo - São Paulo - Brasil \\ kauegeo@gmail.com
}

\section{Resumo}

A mineração é uma das mais importantes atividades econômicas de muitas formações socioespaciais africanas. Nesse contexto, explorado há séculos na África Ocidental, o ouro tornou-se, no século XXI, 0 principal produto da pauta de exportações de Gana, sendo extraído e processado principalmente por grandes capitais estrangeiros e por pequenos capitais nacionais, que estabelecem diversos tipos de relações no país. $\mathrm{Na}$ cadeia produtiva desse minério, atua ainda o Estado, responsável pela elaboração da legislação e da fiscalização no setor. Assim, compreender a organização das forças produtivas e das relações de produção em torno da exploração aurífera contemporânea de Gana é o objetivo deste artigo.

Palavras-chave: Gana, formação socioespacial, mineração, ouro.

\section{Abstract}

Mining is one of the most important economic activities of many African socio-spatial formations. In this context, explored for centuries in West Africa, gold has become, in the 21st century, the main product of the export agenda of Ghana, being extracted and processed mainly by large foreign capitals and by small national capitals, which establish various types of relations in the country. In the production chain of this ore, the State is still responsible for the elaboration of legislation and inspection in the sector. Thus, understanding the organization of productive forces and production relations surrounding contemporary Ghanaian gold exploration is the goal of this paper.

Keywords: Ghana, socio-spatial formation, mining, gold.

\section{Résumé}

L'exploitation minière est l'une des activités économiques les plus importantes de nombreuses formations socio-spatiales africaines. Dans ce contexte, exploré depuis des siècles en Afrique de l'Ouest, l'or est devenu, au 21 ème siècle, le principal produit du programme d'exportation du Ghana, extrait et traité principalement par de grands capitaux étrangers et de petites capitales nationales qui établissent différents types de relations au Ghana. Dans la chaîne de production de ce minerai, l'État est toujours responsable de l'élaboration de la législation et de l'inspection dans le secteur. Ainsi, comprendre l'organisation des forces productives et les relations de production entourant l'exploration ghanéenne contemporaine est l'objectif de cet article.

Mots-clés: Ghana, formation socio-spatiale, exploitation minière, l'or. 
Introdução

Característica comum entre diversos países da África ao sul do Saara, a exploração de recursos minerais corresponde à principal atividade desempenhada pelas forças produtivas atuantes em Gana na contemporaneidade. ${ }^{1}$ Dentre esses recursos, o ouro assume um notório protagonismo, tendo sido responsável por $42 \%$ dos valores obtidos com as exportações do país em 2016, o equivalente a 4,4 bilhões de dólares (OEC, 2018).

Explorado na África Ocidental desde, pelo menos, o século XII, o ouro tornou-se a principal commodity ganense apenas na década de 1990. Esse fato é o resultado das políticas neoliberais do governo do presidente Jerry John Rawlings implementadas na década anterior. Conhecidas como Plano de Ajuste Estrutural (PAE), tais políticas passaram a estimular a entrada de grandes empresas estrangeiras do setor da mineração ganense. Nesse contexto, que se caracterizou de forma genérica pela abertura da economia nacional aos grandes capitais externos, ocorreu também a criação de leis que buscavam regularizar os pequenos capitais nacionais que, até então, mineravam ilegalmente no país.

A caracterização da atuação desses dois tipos de capital, bem como a análise da relação entre eles, é o objetivo deste artigo. Nos últimos anos, importantes estudos têm lançado mão de interpretações sobre o processo de produção do ouro pelas grandes empresas estrangeiras ou pelas pequenas empresas nacionais (Akabzaa; Darimanni, 2001; Hilson, 2014; Nyame; Grant, 2014; Okoh, 2014).

Contudo, a relação entre esses dois tipos de empreendimento dentro de uma mesma cadeia produtiva ainda precisa ser mais estudada, de modo que interessa aqui analisar como ocorre a exploração do ouro em Gana na contemporaneidade, levando em consideração as relações de produção, as forças produtivas disponíveis e a atuação - complementar e conflituosa - desses dois tipos de capital, caracterizados por terem origens e escalas distintas.

Do ponto de vista teórico-metodológico, Gana será analisada neste artigo através do conceito de “formação socioespacial”. Criada por Milton Santos na década de 1970, a formação socioespacial estaria entre as principais contribuições do intelectual brasileiro à geografia (Mamigonian, 1996). Para além disso, o conceito é uma derivação do 
conceito marxista do século XIX de formação econômica social, que busca analisar aquilo que existe de particular no desenvolvimento dos modos de produção pelo mundo, o que possibilita uma compreensão mais complexa sobre a evolução diferencial das sociedades e de suas economias ao longo do tempo (Santos, 1977).

Na década de 1970, Santos argumentava que o espaço - instância negligenciada na grande maioria das análises de economistas, sociólogos e cientistas políticos - também desempenhava um papel importante no desenvolvimento das particularidades nacionais dos modos de produção anunciados por Marx no século XIX. Assim, o geógrafo introduziu a dimensão espacial em sua elaboração conceitual, afirmando que:

As diferenças entre os lugares são o resultado do arranjo espacial dos modos de produção particulares. O ‘valor’ de cada local depende de níveis qualitativos e quantitativos dos modos de produção e da maneira como eles se combinam (Santos, 1977, p. 87).

A importância da utilização do conceito de formação socioespacial se deve também ao fato de que ele constrange as análises generalistas feitas na escala regional ou continental, comuns em estudos de muitos africanistas. Isso não significa dizer, evidentemente, que o modo de produção em Gana não tenha semelhanças ao de outros países, mas sim de entender como tais semelhanças foram forjadas ao longo da História.

Assim, o conceito de formação socioespacial serviu para construir as etapas metodológicas que estruturaram o estudo e a apresentação dos argumentos contidos neste artigo, que se pautaram na sistematização de fontes secundárias - livros, artigos acadêmicos, artigos jornalísticos, anuários estatísticos, leis e decretos do governo - e primárias. Os trabalhos de campo para o território ganense ocorreram em 2013 e em 2016 e neles foram feitas entrevistas abertas e semiestruturadas com diversos tipos de instituições que atuam na economia do país, como ministérios, associações de empresas e empresas públicas e privadas. Ao mesmo tempo, houve o registro das paisagens por meio da descrição densa (Geertz, 1973) e de fotografias. É importante mencionar aqui a dificuldade existente na elaboração de entrevistas com as grandes empresas de mineração os com os pequenos mineradores, uma vez que grande parte deles fala apenas os idiomas locais ou não estava disposta a conceder entrevistas em função do eventual status de ilegalidade de suas atividades. 
Na formação socioespacial ganense (Croqui Cartográfico 1), a extração e o processamento do ouro acontecem fundamentalmente na porção sudoeste do território, onde há a ocorrência das rochas que apresentam concentrações economicamente exploráveis do mineral. O ouro é explorado em minas (superficiais ou em profundidade) ou nas margens de alguns rios (aluvial) e, evidentemente, as circunstâncias de ocorrência do recurso irão demandar usos diferenciados dos meios de produção e da força de trabalho.

Assim, novamente, cabe marcar a distinção fundamental entre o grande e o pequeno capital que conformam, junto ao Estado, a cadeia produtiva do ouro no país. Por um lado, o grande capital estrangeiro é operado em empresas que possuem as mais modernas tecnologias à sua disposição. Além disso, elas contam com portentosos auxílios do governo, seja diretamente (na forma de subsídios produtivos e isenções fiscais), seja indiretamente (na qualidade da oferta de infraestrutura de circulação, distribuição, telecomunicação e energia). Por outro lado, o pequeno capital nacional é operado em empresas que, na maioria das vezes, atuam na informalidade e que têm menos acesso às técnicas mais modernas (e ao capital necessário para obtê-las). Além disso, as linhas de crédito disponíveis são reduzidas, bem como o auxílio governamental.

Desse modo, compreender como esses capitais se organizam e se relacionam dentro de um contexto de relações de produção historicamente construído na formação socioespacial ganense é o que o artigo buscará revelar nas próximas páginas. 


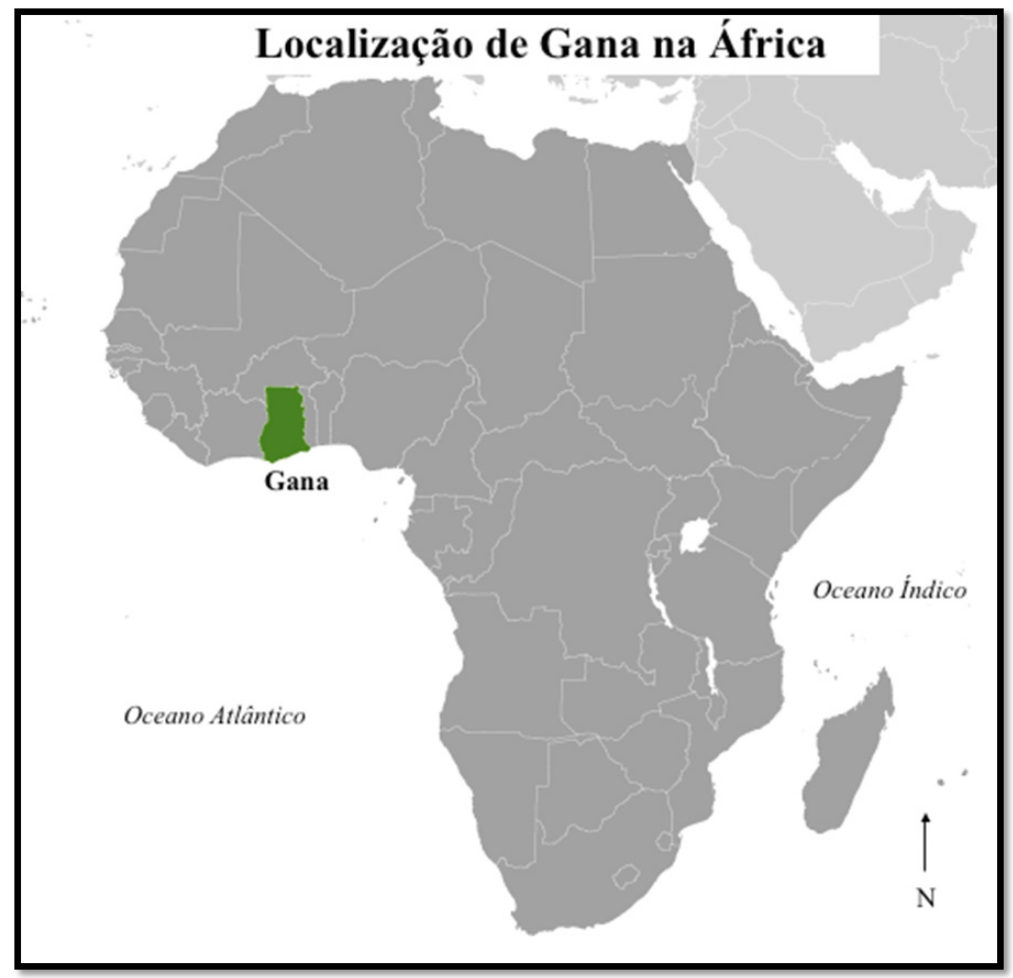

Croqui Cartográfico 1 - Localização de Gana na África.

Fonte: Elaboração do autor com base em CIA World Fact Book (2018). Disponível em: <https:// www.cccarto.com/atlas/goldmines/ghana/index.html.> Acesso em: 15 maio 2018.

As relações de produção do ouro na formação socioespacial ganense

A exploração do ouro pelas sociedades que tinham seus territórios no espaço geográfico onde hoje se localiza a formação socioespacial de Gana é bastante antiga. De modo geral, esse minério integrou os circuitos comerciais transaariano e atlântico - desde os séculos XII e XVI, respectivamente -, suprindo as demandas de mercados localizados no norte da África, na Europa e no Oriente Médio. A exploração do recurso tornou-se tradicional em diferentes reinos da região litorânea da África 
Ocidental, especialmente nas proximidades do Rio Volta, de modo que, nessa região, o reino de maior destaque na mineração aurífera foi o Asante. ${ }^{2}$

No final do século XIX, a colonização do Reino Unido sobre os reinos da região então denominada "Costa do Ouro" subverteu as relações de produção aurífera que vinham sendo desenvolvidas localmente até então. Num primeiro momento, os colonizadores impuseram a propriedade da Coroa britânica sobre os recursos naturais por meio das Land Bills de 1894 e 1897. Desse modo, a produção passou a ser dirigida por grandes empresas mineradoras europeias, cujas técnicas de extração eram capazes de obter produções maiores que aquelas utilizadas pelas sociedades locais. A predominância do capital estrangeiro na exploração mineral da Costa do Ouro perdurou até o fim do período colonial (Boahen, 1975). ${ }^{3}$

Com a independência do jugo britânico, em 1957, a formação socioespacial ganense surge e, por meio da soberania de um Estado autóctone, passa a planejar as forças produtivas e as relações de produção de formas distintas ao período anterior. Nesse sentido, entre os anos que se estenderam da independência até meados da década de 2010, pode-se identificar dois períodos distintos no que tange à organização das forças produtivas na mineração do ouro em Gana: o primeiro se desenvolve entre 1957 e 1986 e o segundo entre 1986 e os dias de hoje.

No primeiro período, a atividade de extração e processamento mineral realizou-se, essencialmente, por meio do capital estatal. A bem da verdade, o desenvolvimento do setor mineiro não figurava como a prioridade econômica do governo, uma vez que a maior parte das divisas do país era obtida por meio da produção e da exportação de cacau e madeira (Anin, 1989). De todo modo, tanto na gestão de Kwame Nkrumah (1957-1966) quanto na de Ignatius Acheampong (1972-1978), foi estabelecida uma série de medidas responsáveis pela estatização do setor.

Em 1961, foi fundada a State Gold Mining Corporation (SGMC). Essa empresa estatal incorporou cinco minas de ouro que, até então, eram exploradas por empresas britânicas e que estavam prestes a fechar: Bibiani, Tarkwa, Prestea (Western Region), Konongo (Ashanti Region) e Dunkwa (Central Region). O principal objetivo do governo na aquisição dessas minas foi evitar a ampliação do desemprego no país com o possível fechamento delas. No ano seguinte, em 1962, aprovou-se a Mineral Act, lei que "concedeu ao Estado o domínio sobre todos os minerais localizados no 
território da República de Gana e daqueles localizados em seus territórios marítimos” (Anin, 1989, p.33, tradução nossa).

O projeto de tornar o Estado a instituição central das relações de produção na mineração intensificou-se durante a presidência de Acheampong: com o auxílio de um decreto conhecido como Mining Operation Decreet, ficou definido em seu governo que 55\% da composição do capital da Ashanti Goldfields Corporation (AGC) - maior mineradora que atuava em Gana na época ${ }^{4}$ - passaria a pertencer ao governo. Com isso, a AGC acabou efetuando a transferência de sua sede de Londres para Acra no mesmo ano (Anin, 1989).

No que diz respeito à produtividade durante esse primeiro período, pode-se observar uma certa estabilidade na década de 1960 e no início dos anos 1970. Todavia, as crises do petróleo, a desvalorização dos preços das commodities no mercado internacional e os numerosos problemas internos da economia ganense - elevadas taxas de importação, sobrevalorização da moeda ganense, o cedi, redução dos investimentos na indústria e altas inflação e corrupção - justificaram uma sensível redução dos investimentos estatais no setor e, consequentemente, uma visível queda na produção em fins da década de 1970 e na década de 1980.

Diante desse cenário, em 1979, durante a presidência de Hilla Limman, um comitê foi criado com o objetivo de analisar a situação da atividade mineradora e elaborar sugestões para aumentar a sua produtividade. Finalizado em 1980, o relatório, denominado Quarshie Report $^{5}$, assegurava que:

O atual nível deprimido da produção de ouro pode ser atribuído a vários fatores, incluindo: fraco planejamento, falta de desenvolvimento das jazidas minerais, obsolescência das fábricas e dos maquinários e falta de recursos financeiros e humanos (Anin, 1989, p.39, traduzido do inglês).

No relatório mencionavam-se ainda outros fatores agravantes ao desenvolvimento das forças produtivas na mineração, como: precariedade da infraestrutura ferroviária, rodoviária e portuária; escassez e alto custo de alimento para os trabalhadores (em função da inflação e da crise de abastecimento de alimentos enfrentada pelo país no final da década de 1970 e no início de 1980), e frequência das práticas de roubo e contrabando de ouro nas áreas de exploração (Anin, 1989). 
O Quarshie Report contribuiu de maneira oportuna na construção dos discursos políticos que questionaram a eficiência do capital estatal na economia nacional, corroborando ideologicamente as políticas econômicas que vieram a ser adotadas ao longo da década de 1980, estruturadas sob a doutrina neoliberal. Desse modo, nesse momento específico ocorreu uma gradativa reorganização normativa que resultou na alteração das relações de produção na atividade mineradora com o argumento de que havia uma necessidade de se ampliar a produção de ouro no país.

A medida mais importante tomada pelo governo Rawlings para viabilizar o crescimento econômico da mineração foi a introdução da Minerals and Mining Law (PNDC 153), de 1986 (Hutchful, 2002). Essa lei atraiu grandes capitais estrangeiros e, ao mesmo tempo, regularizou a atividade de mineração de pequeno capital nacional. Referente às atribuições do Estado diante desse novo contexto econômico, Hutchful menciona que essa lei: “[...] Estabeleceu a Mineral Commision para regular o setor e liberalizar mais o cenário da mineração, criando benefícios significativamente novos para os investidores da área” (Hutchful, 2002, p. 83, tradução nossa).

A abertura do mercado aos novos investimentos - somada à gradual privatização das estatais ganenses (criadas no período anterior) - fez com que o Estado fosse convertido em um verdadeiro regulador da atuação de empresas privadas por meio de agências estatais, como a supracitada Mineral Commision e o Geological Survey Department. Contudo, é importante salientar que a lei de 1986 também reafirmou a propriedade do Estado sobre todos os recursos minerais disponíveis no território. Segundo Anin, "o governo tem o poder de obter de forma compulsória qualquer terreno que possa ser requisitado para garantir o desenvolvimento ou a utilização de seus recursos minerais” (Anin, 1989, p.48, tradução nossa).

Como resultado imediato dessa transformação legal, mais de 55 licenças de prospecção de ouro foram concedidas entre 1986 e 1989 a empresas privadas, sendo que três companhias começaram a produzir já no final de 1990: a Bogosu Resources (canadense); a Goldenrae Mining (uma joint venture entre a luxemburguesa IMT International of Luxembourg, a canadense Sikaman Gold Resources of Canada e o governo ganense), e a Teberebie Goldfields Limited (joint venture estadunidense e ganense) (Hutchful, 2002). 
Em 2006, a Minerals and Mining Law foi substituída pela Minerals and Mining Act (Act 703), que reafirmou a propriedade estatal sobre os recursos minerais, logo no primeiro artigo (Campbell, 2009, tradução nossa). Essa nova legislação foi mais atrativa aos investimentos estrangeiros, já que reduziu os impostos no setor e manteve as condições favoráveis de incentivos estatais (Quadro 1).

Atualmente, as relações de produção em Gana se organizam a partir do Ministry of Lands and Natural Resources que, por meio do Geological Survey Department e da Mineral Commision, acompanha todos os aspectos da mineração no país: o primeiro providencia as informações geológicas atualizadas sobre o território, enquanto o segundo é responsável pela regulamentação e pela administração dos recursos minerais, além de coordenar as políticas relativas à atividade (e através de sua Inspectorate Division, a Mineral Commision institui os padrões ambientais, de saúde e segurança para as empresas que operam no país) (Ghana Chamber of Mines; International Council on Mining and Metals, 2015).

\begin{tabular}{|l|c|c|}
\hline Itens & $\begin{array}{l}\text { Mineral and Mining } \\
\text { Law (Lei PNDCL 153) } \\
\mathbf{1 9 8 6}\end{array}$ & $\begin{array}{l}\text { Minerals and Mining Act } \\
\text { (Lei Act 703) } \\
\mathbf{2 0 0 6}\end{array}$ \\
\hline Abono de capital inicial & $75 \%$ & $75 \%$ \\
\hline Subsequente abono de capital & $50 \%$ & $50 \%$ \\
\hline Abono de investimento & $5 \%$ & $5 \%$ \\
\hline Perdas acumuladas (por motivos de taxação) & $25-80 \%$ & $25-80 \%$ \\
\hline $\begin{array}{l}\text { Abono de pesquisa e desenvolvimento; } \\
\text { direito de importação; imposto cambial }\end{array}$ & isento & $25 \%$ \\
\hline Imposto de renda & $45 \%$ & $3-6 \%$ \\
\hline Royalties & $3-12 \%$ & $10 \%$ \\
\hline Imposto retido na fonte & $10 \%$ & $10 \%$ \\
\hline Imposto sobre ganhos de capital & $10 \%$ & $0 \%$ \\
\hline Imposto de lucro adicional & $25 \%$ & $10 \%$ \\
\hline $\begin{array}{l}\text { Outras (participação do capital público na } \\
\text { concessão da área licenciada) }\end{array}$ & $10-30 \%$ & \\
\hline
\end{tabular}

Quadro 1 - Incentivos fiscais e taxas na mineração em Gana segundo a Minerals and Mining Law (1986) e a Minerals and Mining Act (2006). 
Nesse sentido, existem três tipos de licenças concedidas pelo Ministry of Lands and Natural Resources às empresas que objetivam operar em Gana: a Licença de Reconhecimento, a Licença de Prospecção e a Concessão de Mineração (KPMG Global Mining Institute, 2014).

A Licença de Reconhecimento dura no máximo um ano, podendo ser renovada por mais um ano. A área da licença pode chegar a $5 \mathrm{mil}$ blocos contíguos (cada bloco equivale a aproximadamente 21 hectares). $\mathrm{O}$ detentor dessa licença pode realizar apenas levantamentos geoquímicos e fotogeológicos, sendo permitido ainda utilizar outras técnicas de sensoriamento remoto (KPMG..., 2014).

Em seguida, a empresa pode solicitar uma Licença de Prospecção. Essa licença dura três anos e pode ser renovada por mais três. A área concedida é de 750 blocos e, quando há renovação, a concessão limita-se entre 125 e 375 blocos. Essa licença confere o direito exclusivo de busca por um mineral específico. As investigações geológicas, geofísicas e geoquímicas, além de perfurações e prospecções (e outras técnicas subterrâneas), permitem determinar a extensão e o valor econômico das reservas minerais (KPMG..., 2014).

Por fim, caso sejam encontrados depósitos com valor comercial que justifiquem uma exploração de longo prazo, a empresa solicita a "Concessão de Mineração". Tal concessão dura 30 anos e pode ser renovada por outros 30. A área concedida é de, no máximo, 300 blocos contíguos. Além dessa concessão, concedida pelo Ministry of Lands and Natural Resources, a empresa deve também obter permissões da Forestry Commision, da Environmental Protection Agency e da Water Resources Commision (KPMG..., 2014).

De modo geral, as políticas de abertura da economia, desde a década de 1980, asseguraram a entrada de empresas estrangeiras altamente capitalizadas e munidas de eficientes técnicas de produção. Ao mesmo tempo, pequenos mineradores também integraram a atividade, porém, dispondo de outras condições produtivas. A soma dessas duas escalas de operação foi responsável pelo crescimento da produção mineral no país entre 1985 e 2010.

Dadas as relações de produção contemporâneas, cabe analisar de que modo as forças produtivas se organizam em torno do grande e do pequeno capital. Na organização da cadeia produtiva do ouro em Gana, essas duas escalas de capital contam ainda com numerosas empresas 
que auxiliam na extração e no processamento mineral, na consultoria para tomadas de decisões administrativas, logísticas e financeiras, no comércio que supre as demandas por matérias-primas e maquinários diversos. Contribuem também para o funcionamento da cadeia todas as infraestruturas que asseguram o fluxo de pessoas, capital, informação, energia e mercadorias.

\section{A exploração do ouro ganense pelo grande capital externo}

Desde fins do século XX até os dias de hoje, a atuação do grande capital na exploração aurífera de Gana encontra-se nas mãos de poucas empresas - todas elas estrangeiras (ver Quadro 2) - que, juntas, chegaram a responder por aproximadamente $65 \%$ da produção do território em meados da década de 2010. Invariavelmente, todas essas empresas estabeleceram suas sedes regionais na capital Acra, de onde administram a produção, a circulação e a distribuição do recurso para outros países.

Do ponto de vista das técnicas utilizadas nos meios de produção, esse grande capital externo lança mão de modernos maquinários que viabilizam a extração do ouro e o seu processamento em bulhões. A maior parte desses bens de capital é importada a partir do momento em que essas empresas obtêm a "Concessão de Mineração" junto ao governo. Contudo, nas proximidades das áreas de extração e processamento aurífero, são frequentemente encontrados estabelecimentos comerciais que vendem diferentes tipos de equipamentos - novos ou usados - necessários às primeiras etapas da cadeia produtiva do ouro.

Do ponto de vista normativo, esse mesmo capital conta com o apoio local da Ghana Chamber of Mines ${ }^{6}$ que, além de oferecer uma grande variedade de serviços jurídicos e burocráticos, garante também parcerias no âmbito de serviços logísticos, e financeiros, geralmente ofertadas por empresas nacionais. No que tange à força de trabalho, a mineração feita pelo grande capital estrangeiro chegou a empregar, em meados da década de 2010, mais de 15 mil pessoas, a maioria absoluta formada por ganenses que ocupam os mais diversos cargos profissionais associados aos trabalhos braçais e administrativos. 


\begin{tabular}{|c|c|c|c|}
\hline Empresa & $\begin{array}{l}\text { País de origem/ } \\
\text { sede internacional }\end{array}$ & $\begin{array}{l}\text { Ano de } \\
\text { fundação }\end{array}$ & Operações em Gana \\
\hline Anglogold Ashanti & $\begin{array}{l}\text { África do Sul } \\
\text { Johanesburgo }\end{array}$ & 2004 & $\begin{array}{l}\text { Obuasi (Ashanti Region) } \\
\text { Idupriem (Western Region) }\end{array}$ \\
\hline Goldfields & $\begin{array}{l}\text { África do Sul } \\
\text { Johanesburgo }\end{array}$ & 1887 & $\begin{array}{l}\text { Damang (Western Region) } \\
\text { Tarkwa (Western Region) }\end{array}$ \\
\hline $\begin{array}{l}\text { Golden Stars } \\
\text { Resources }\end{array}$ & $\begin{array}{l}\text { Canadá } \\
\text { Toronto }\end{array}$ & 1992 & $\begin{array}{l}\text { Wassa (Western Region) } \\
\text { Prestea (Western Region) }\end{array}$ \\
\hline Chirano Gold Mine & $\begin{array}{l}\text { Canadá } \\
\text { Toronto } \\
\text { (subsidiária do Grupo Kinross Gold Corporation) }\end{array}$ & 1993 & Chirano (Western Region) \\
\hline $\begin{array}{l}\text { Newmont Mining } \\
\text { Corporation }\end{array}$ & $\begin{array}{l}\text { Estados Unidos } \\
\text { Denver }\end{array}$ & 1921 & $\begin{array}{l}\text { Ahafo (Brongo Ahafo } \\
\text { Region) } \\
\text { Akyem (Eastern Region) }\end{array}$ \\
\hline Adamus Resources & $\begin{array}{l}\text { Canadá } \\
\text { Vancouver } \\
\text { (subsidiária do Grupo Endeavour Mining } \\
\text { Corporation) }\end{array}$ & 2001 & Nzema (Western Region), \\
\hline $\begin{array}{l}\text { Perseus Mining } \\
\text { Limited }\end{array}$ & $\begin{array}{l}\text { Austrália } \\
\text { Subiaco }\end{array}$ & 2003 & Ayanfuri (Central Region). \\
\hline
\end{tabular}

Quadro 2 - Principais empresas estrangeiras de mineração aurífera que atuam em Gana (meados da década de 2010).

Fonte: Elaboração do autor como base em: Anglogold Ashanti, 2016; Gold Fields, 2016; Golden Stars Resources, 2016; Kinross Gold Corporation, 2016; Newmont Mining Corporation, 2016; Endeavour Mining Corporation, 2016; Perseus Mining Limited, 2016; Ghana Chamber of Mines, 2015; International Council on Mining and Metals, 2015.

Nesse cenário, o Ghana Mine Workers Union (GMWU) é o sindicato que representa o interesse dos mineiros, tendo sido fundado em 1944, durante o período colonial. Ele atua no sentido de aglutinar forças diante das reinvindicações coletivas (geralmente associadas a reajustes salariais e melhorias das condições de trabalho), de oferecer diferentes tipos de treinamentos profissionais e de prover suporte legal aos trabalhadores (como oferecer advogados e auxiliar em tramitações de processos trabalhistas) (Ghana Mine Workers Union, 2016).

A compreensão sobre a exploração do ouro pelo grande capital externo na formação socioespacial ganense deve levar em consideração também o funcionamento de diferentes infraestruturas: as rodovias 
asfaltadas e bem sinalizadas que garantem a chegada dos trabalhadores, das máquinas e dos insumos às áreas de extração e processamento do mineral; as redes de eletricidade e telecomunicações, que garantem a fluidez de informação, capital e energia elétrica; além das infraestruturas de água e saneamento básico. É importante mencionar, contudo, que esta não é a realidade da maior parte do território em questão: os desequilíbrios regionais no país, em especial pelo fato de que as melhores infraestruturas se concentram nas porções centro-sul da formação socioespacial, justamente onde se localiza a maior parte dos recursos naturais exportados por Gana.

Nessa cadeia produtiva, há também as infraestruturas aeroviárias, que garantem a circulação e a distribuição dos bulhões produzidos: semanalmente um helicóptero transporta o ouro das zonas de produção até o Aeroporto Internacional de Kotoka, em Acra. Esse transporte é feito por empresas privadas - como a britânica G4S, que realiza serviços de segurança em mais de 125 países do mundo (G4S, 2016) - e não ocorre por rodovias por duas principais razões: volume transportado e segurança sobre a carga.

Por fim, no aeroporto, os bulhões passam por uma série de vistorias por parte das empresas mineradoras e do governo antes de serem exportados às refinarias localizadas em outros países, como: a Refinaria Rand, na África do Sul; a Refinaria CT, na Coreia do Sul; a Refinaria Takai, no Japão, ou a Valcambi, na Suíça. Existem planos de desenvolver refinarias no país há anos, contudo o déficit na oferta de energia elétrica tem sido um dos maiores entraves à execução de qualquer projeto de industrialização (Ghana...; International... , 2015).

\section{A exploração do ouro ganense pelo pequeno capital nacional}

A prática da pequena mineração - também chamada de mineração artesanal - realizou-se ao longo de séculos por diferentes povos que habitaram a área onde atualmente se localiza o território ganense, dentre os quais destacaram-se os asantes. No entanto, em 1933 - durante o período colonial -, a Coroa Britânica promulgou a chamada Mercury Law, que proibia a utilização de mercúrio na colônia. Com isso, inviabilizou-se a produção de ouro por iniciativas pouco capitalizadas, que usavam 
o elemento químico como recurso fundamental na produção aurífera (Akabzaa; Darimani, 2001).

Diante dessa lei, restaram aos pequenos mineradores duas opções: operar na ilegalidade - fazendo uso de mercúrio contrabandeado - ou empregar-se em grandes empresas mineradoras europeias que atuavam na colônia. Nem mesmo a independência de Gana do jugo colonial resolveu o impasse, uma vez que a Mercure Law foi mantida pelos governos após 1957.

É apenas em 1989, com a aprovação da Small-scale Mining Law, que as operações de pequenos mineradores recuperaram o status de legalidade (Akabzaa; Darimani, 2001). Desde então, a participação da mineração em pequena escala no total da produção aurífera ganense tornou-se maior a cada ano, tendo alcançado aproximadamente 35\% do total da produção nacional em meados da década de 2010 (Ghana...; International..., 2015).

A definição para mineração em pequena escala não é precisa, sendo que, geralmente, ela é atribuída para qualquer área de concessão que seja inferior a $100 \mathrm{~m}^{2}$ (Hilson et. al., 2014; Precious Minerals Marketing Corporation, 2016). Segundo Nyame e Grant, essa escala de atividade exibe diferentes formas de organização. Os autores asseguram que:

A pequena mineração artesanal varia amplamente em termos de escala, nível de tecnologia e grau de organização. Ela pode ser conduzida por apenas uma pessoa ou até por algumas centenas e a tecnologia empregada vai desde pás rudimentares, picaretas e peneiras até escavadoras sofisticadas (Nyame; Grant, 2014, p.77, traduzido do inglês).

Dentre as diferentes atividades operadas nas pequenas mineradoras artesanais, podem ser citadas: exploração, prospecção e processamento (lavagem) dos minerais, transporte e venda aos intermediários comerciais (Nyame; Grant, 2014).

Os mineradores em pequena escala apresentam uma significativa mobilidade espacial que é decorrente de eventuais situações de escassez mineral: cerca de $70 \%$ desses mineiros já migraram pelo território ganense em função do esgotamento das reservas de ouro nas áreas onde trabalhavam. Junto a eles, também migram os pequenos investidores desse tipo de mineração e algumas atividades econômicas acessórias - sobretudo as comerciais (venda de alimentos, de medicamentos, de insumos à 
produção e de objetos diversos, inclusive aparelhos de celular) e as de serviços (de manutenção e reparo do maquinário) (Nyame; Grant, 2014).

A baixa capitalização da mineração em pequena escala significou, durante muito tempo, um menor acesso à informação sobre a localização das melhores reservas auríferas do país, já que tais informações são disponibilizadas por custosos estudos e mapeamentos geológicos. Desse modo, tradicionalmente, os pequenos mineiros optam pela exploração aluvial, pois a detecção de ouro nos rios é mais simples do que no substrato rochoso, além de representar menores custos com os instrumentos e maquinários.

Ainda assim, é possível encontrar pequenos grupos de mineiros que fazem escavações subterrâneas utilizando instrumentos simples pás, cordas e madeiras - e construindo minas artesanais (Imagem 1). Nessas pequenas minas eles retiram fragmentos rochosos e levam até a superfície para que sejam processados em dois tipos de máquinas diferentes: na crusher, que fragmenta a rocha em uma granulometria ainda alta (Imagem 2), e na smother, que reduz mais a granulometria do material (Imagem 3). Geralmente essas máquinas são compradas usadas, importadas e demandam bastante energia elétrica, garantida, eventualmente, por geradores próprios. Esse material vai para tanques de decantação (Imagem 4) e, em seguida, é colocado em reação química com mercúrio em pequenas bacias (Imagem 5), de onde o ouro é extraído (Imagem 6). 


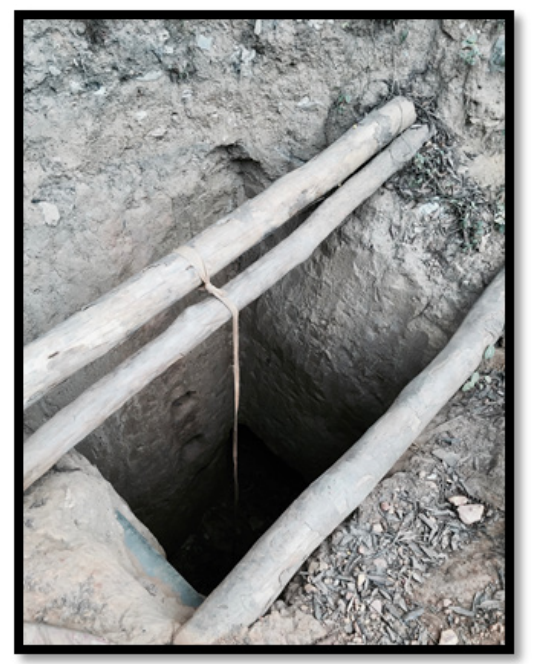

Imagem 1 - Entrada de mina subterrânea artesanal em Tarkwa (Western Region) Gana, 2016. Fonte: Elaboração do autor (2016).

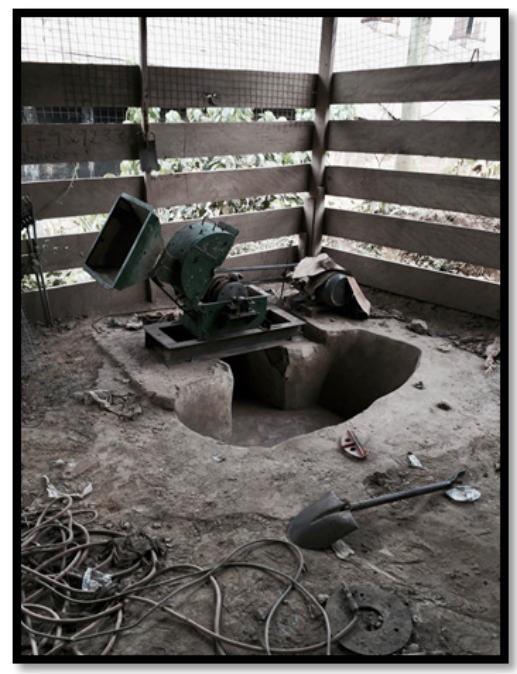

Imagem 2 - Máquina de fragmentação de rochas (crusher) em estabelecimento de pequena mineração em Tarkwa (Western Region). Gana, 2016.

Fonte: Elaboração do autor (2016). 


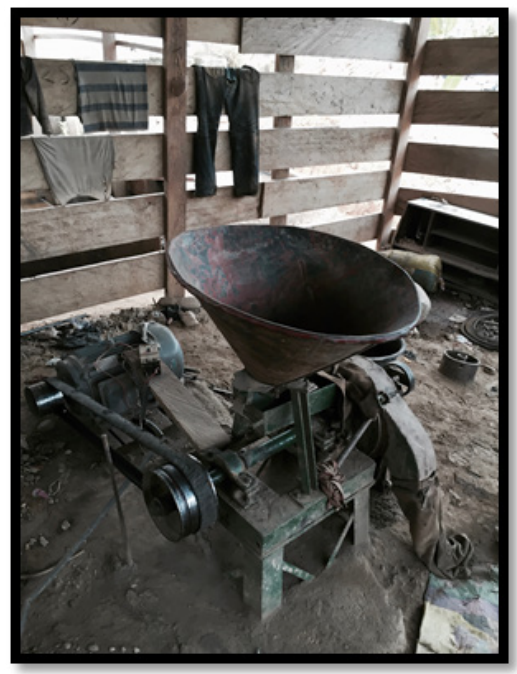

Imagem 3 - Máquina de fragmentação de rochas (smother) em estabelecimento de pequena mineração em Tarkwa (Western Region). Gana, 2016

Fonte: Elaboração do autor (2016).

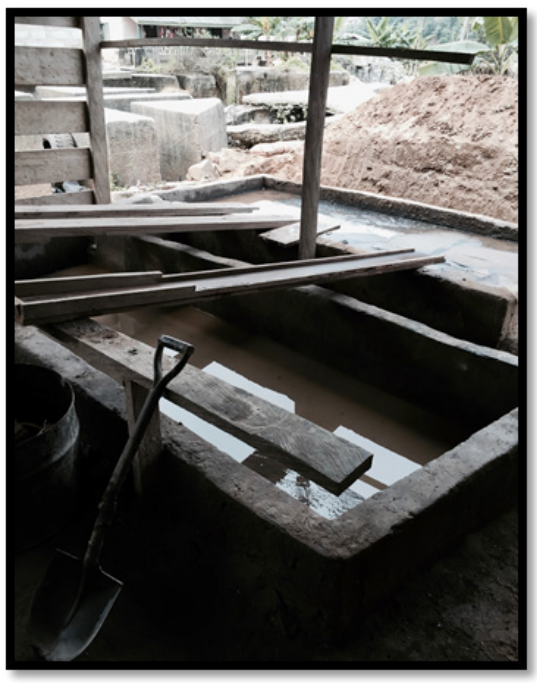

Imagem 4 - Tanques de decantação em Tarkwa (Western Region). Gana, 2016.

Fonte: Elaboração do autor (2016). 


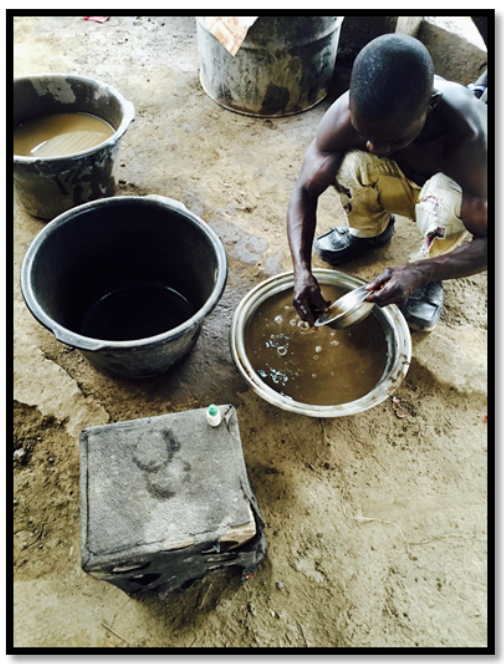

Imagem 5 - Minerador misturando ouro e mercúrio em Tarkwa (Western Region). Gana, 2016.

Fonte: Elaboração do autor (2016).

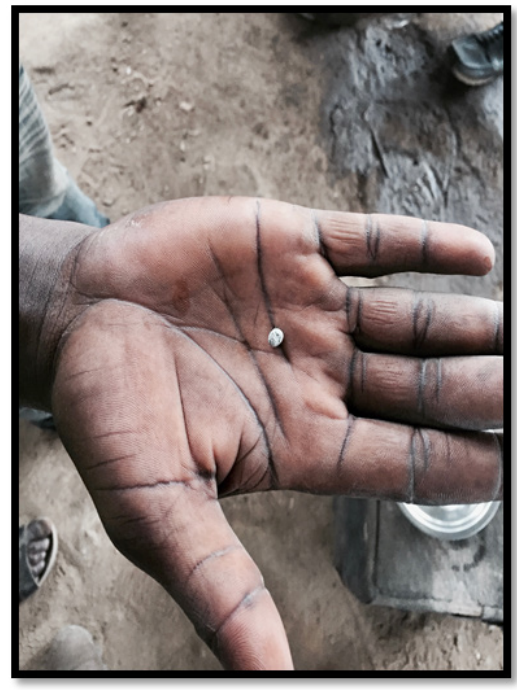

Imagem 6 - Pepita de ouro produzida por pequenos mineradores em Tarkwa (Western Region). Gana, 2016.

Fonte: Elaboração do autor (2016). 
A ocorrência de mineradores que não dispõem de licença do governo para explorar ouro é grande. Esses mineradores são chamados localmente de "galamsey", termo derivado de uma redução da expressão inglesa gather them and sale (junte e venda). Eles operam sem registro e sua atividade é considerada, portanto, ilegal. Geralmente, os galamsey afirmam que o custo para obtenção de licença de exploração é muito elevado, inviabilizando seu acesso legal aos recursos naturais do país. Hilson et. al. explicam que:

O exorbitante custo de registo tem provado ser o maior desafio para o prospector descalço. Além das evidências - que apontam que as taxas de licenciamento são superiores às condições financeiras dos candidatos - o governo ainda optou em aumentá-las. As licenças de prospecção atualmente custam 1.000 cedis, ou 512 dólares, para preparar a área de exploração; 100 cedis (51 dólares) para o formulário de requerimento; 250 cedis (128 dólares) para a taxa de processamento; 550 cedis (282 dólares) de taxa de consideração; 750 cedis (384 dólares) para a Agência de Proteção Ambiental, para uma conclusão de uma avaliação de impacto ambiental; entre outras taxas, incluindo imposto de selo, impostos judiciais e de registro fundiário (Hilson et. al., 2014, p.298, tradução do inglês).

Além das dificuldades em regularizar a situação por questões financeiras, grande parte dos mineradores de ouro em pequena escala também sofre com a falta de linhas de crédito (públicas ou privadas) e de auxílios governamentais para o desenvolvimento (profissionalização) da atividade (Hilson et. al., 2014).

Somam-se ainda, nesse cenário, os numerosos conflitos que ocorrem entre os galamsey e os mineradores regulamentados, sejam estes os de pequeno ou aqueles de grande capital. Tais conflitos são marcadamente territoriais, já que os galamsey são frequentemente acusados - pelos regulamentados - de ocupar áreas licenciadas a outras empresas e, dadas as condições precárias de suas operações, são também acusados de criar uma série de impactos no meio ambiente, como desflorestamento, assoreamento de rios e poluição de rios e do solo (Okoh, 2014).

De modo geral, o aumento da produção aurífera via mineração em pequena escala está associado não apenas à regularização da atividade, mas também à valorização do preço do ouro no mercado mundial desde o início do século XXI. Não apenas ganenses de diferentes origens e formações (alguns inclusive ex-trabalhadores de grandes empresas 
mineradoras) se lançaram na atividade, mas também pessoas de outras formações socioespaciais da África Ocidental (Costa do Marfim, Togo e Burkina Faso) e também da China.

Um aspecto importante a ser considerado sobre esse tipo de mineração é como o seu dinamismo está associado à melhoria nas condições das infraestruturas de circulação e telecomunicações, em especial da telefonia móvel. Nesse sentido, Nyame e Grant estabelecem uma detalhada caracterização do contexto recente:

Nos últimos anos, as melhorias nas estradas e nas redes de telecomunicação abriram frentes de mineração em algumas regiões de Gana até então inacessíveis, conectando a chamada hinterland às áreas urbanas. Como resultado, os operadores das minerações em pequena escala agora são capazes de se movimentar de maneira mais fácil e rápida, de um lugar a outro, pelo país. Além disso, fundamentalmente, os equipamentos de mineração podem ser transportados para áreas de mineração até então inacessíveis. Concomitantemente, as operadoras de telefonia móvel, como MTN, Vodafone, Tigo e, mais recentemente, a Glo, ampliaram sua cobertura e funcionam em muitas áreas rurais. Agora, a comunicação pode ocorrer prontamente entre as pessoas, até mesmo em áreas remotas, como as áreas de mineração (Nyame; Grant, 2014, p.79, tradução do inglês).

Apesar de ser comum o discurso crítico ao governo por parte dos pequenos mineradores (pois a obtenção de licença é muito custosa e poucos são os incentivos, subsídios e isenções fiscais oferecidas a eles pelo Estado), deve-se atentar para a presença fundamental do Estado relativa à compra e à comercialização do ouro produzido. Desde 1989, a Precious Mineral Marketing Company (PMMC) - empresa estatal fundada em 1963 com o nome de Ghana Diamond Marketing Board - tornou-se responsável pela compra de ouro da mineração em pequena escala, vendendo-o, em seguida, para o mercado externo ou para compradores nacionais. Entre 1989 e 2010, a companhia comprou 24 toneladas de ouro, o que correspondeu a cerca de 467 milhões de dólares no período. Com sede na capital Acra, a PMMC objetiva também reduzir o contrabando do minério.

Muitas vezes, a venda do ouro ao PMMC não é feita diretamente entre os mineiros e a empresa estatal. Nas áreas de produção, sobretudo nos arredores de Obuasi e Tarkwa, multiplicam-se os chamados "compradores de ouro” que, além de servirem como intermediários comerciais, realizam 
etapas do processamento do mineral, como o derretimento em bulhões. Geralmente, tais empreendimentos são de pequeno porte e podem pertencer a pequenos empresários ganenses, ganenses de ascendência sírio-libanesa ou até mesmo a chineses. Elas compram o ouro dos galamsey e, uma vez processado o minério, realizam o transporte até Acra em veículos próprios. Lá realizam a venda ao PMMC.

Existem também muitas pequenas empresas de mineração, devidamente regularizadas, que dispensam esses intermediários comerciais e realizam por si próprias o processamento do mineral em bulhões - geralmente utilizando maquinários de segunda mão -, o transporte dele (por via rodoviária em veículos próprios) e sua venda ao PMMC. Uma vez vendido ao PMMC, a empresa estatal se responsabiliza pela exportação do ouro por via aérea, também escoando a mercadoria do Aeroporto Internacional Kotoka para refinarias espalhadas pelo mundo.

Considerações finais: a complementaridade dos capitais e o Estado atento

A exploração contemporânea do ouro na formação socioespacial de Gana revela importantes dinâmicas que podem auxiliar análises de outros territórios não apenas do continente africano, mas possivelmente da maior parte do Sul Global na qual a atividade de mineração mobiliza significativa parte das forças produtivas.

Entre as principais relações de complementaridade que o grande capital estrangeiro e o pequeno capital (sobretudo nacional) estabelecem, podem-se listar os seguintes:

- a decisão locacional dos pequenos mineradores é influenciada (e, em muitos casos, determinada) pela decisão locacional das grandes empresas de mineração (após estas investirem volumosos recursos em pesquisa, em levantamentos geológicos, geoquímicos e em prospecções), com exceção das áreas de exploração mais antigas;

- a obtenção de maquinários e instrumentos necessários à extração e ao processamento aurífero (sobretudo no caso de minas subterrâneas artesanais) se dá através da compra de equipamentos de segunda mão (no caso dos mineiros menos capitalizados) que, muitas vezes, foram dispensados pelas grandes empresas em função de sua obsolescência. Os 
grupos de pequenos mineiros mais capitalizados conseguem, eventualmente, consumir insumos das mesmas lojas que vendem para o grande capital;

- muitos pequenos mineiros adquiriram experiência profissional por terem trabalhado em grandes empresas do setor.

Contudo, concluir que a presença do grande capital é o fator original na presença dos pequenos mineradores é um notável equívoco histórico, uma vez que a atividade aurífera artesanal é realizada na região desde, pelo menos, o século XII. O que ocorre, efetivamente, é uma complementaridade, na qual o pequeno capital apoia-se em alguns aspectos da atuação do grande. Longe de ser amigável, o cruzamento dessas duas escalas de empreendimentos provoca, também, conforme já mencionado, diversos conflitos de caráter territorial, no que tange à delimitação de áreas de concessão.

Por fim, é importante estabelecer a relação que essas duas escalas de capital operam junto ao Estado ganense. A priori, ambas se beneficiaram com as inovações legislativas do final da década de 1980. No entanto, as vantagens oferecidas às grandes empresas estão em um patamar de custos que a maior parte dos pequenos mineradores não consegue alcançar, já que nem mesmo o capital para obter uma concessão de terras junto ao governo eles possuem. De acordo com Hilson et al.:

Por mais de três décadas, os políticos influentes priorizaram o desenvolvimento do setor de mineração do ouro em grande escala, provendo uma série de generosos incentivos fiscais na tentativa de atrair investimentos externos. Mas, ao mesmo tempo, os sucessivos governos ignoraram as necessidades dos pequenos mineradores de ouro ganenses, implementando e modificando estruturas regulatórias que têm desencorajado, mais que facilitado, sua legalização (Hilson et al., 2014, p. 293, tradução do inglês).

Em outras palavras, ao mesmo tempo em que a situação foi legalizada para os pequenos mineiros, as condições de acesso destes à legalidade de suas operações encontrou uma série de constrangimentos financeiros, superados apenas por aqueles empreendedores mais capitalizados. Aos demais sobrou a ilegalidade, a mesma promulgada nos tempos coloniais da Mercure Law.

Em linhas gerais, a atuação de empresas estrangeiras altamente capitalizadas e de pequenos mineradores (na maioria das vezes nacionais) 
na mesma cadeia produtiva revela relações importantes e dinâmicas econômicas que podem auxiliar nas análises sobre a mineração não apenas em Gana, mas certamente em outros países africanos e do Sul Global.

\section{Notas}

1 Gana está localizada em um continente que apresenta um dos maiores potenciais de exploração de commodities da atualidade. Estima-se que a África possua: $42 \%$ da bauxita mundial; $35 \%$ do urânio; $42 \%$ do ouro; $57 \%$ do cobalto; $39 \%$ do manganês; $73 \%$ da platina; $88 \%$ dos diamantes; $10 \%$ do petróleo, e $5 \%$ do cobre (Grant, 2015).

2 No território do Reino Asante, o ouro era encontrado tanto em minas como em rios (o denominado ouro de aluvião), o que viabilizou o desenvolvimento de sofisticadas técnicas de mineração e garimpo. A extração de ouro em minas era um processo extremamente complexo, de modo que a primeira dificuldade residia em encontrá-lo. Feito isso, dava-se início à construção de poços e à remoção de terra e rochas por meio de instrumentos manuais. Em seguida, o minério deveria ser fragmentado com a mão para, na sequência, ir ao forno, de onde o ouro seria liberado dos outros minerais. Já o ouro de aluvião era encontrado nos rios em finos fragmentos de rocha que eram peneirados e analisados minuciosamente. De uma forma ou de outra, essas técnicas permitiram segundo os cálculos do historiador francês Raymond Mauny - uma produção anual de aproximadamente quatro toneladas de ouro ao longo do século XVI (Davidson, 1985).

3 Boahen identifica o pioneirismo da mineração moderna na Costa do Ouro em Tomas Hughes, nascido e educado na cidade de Cape Coast. No começo dos anos 1860, Hughes chegou a importar maquinários para explorar o ouro em Wassa (na região ocidental da colônia). Apesar de ter conseguido explorar uma rica reserva em 1861, o chefe local ordenou que ele parasse as operações e seus maquinários foram destruídos. Anos mais tarde, em 1877, o comerciante e aventureiro francês conhecido como "Bonnat" criou uma companhia - a African Gold Coast Company - e adquiriu a primeira de muitas concessões para exploração no distrito de Tarkwa (Western Region). Suas operações começaram em 1878 e aumentaram a corrida pelo ouro na colônia, dando origem a várias companhias de exploração mineral (Boahen, 1975).

4 A Ashanti Goldfields Corporation (AGC) iniciou suas atividades na Costa do Ouro no final do século XIX: em 1897, o britânico E. A. Cade (da empresa Smith and Cade Company) comprou uma mina em Obuasi (Ashanti Region) onde trabalhavam mais de 200 pessoas. Essa mina estava sob direção de três ganenses (J.E. Ellis, J. E. Biney e J. P. Brown) que cederam à oferta de Cade. Anos mais tarde, a Smith and Cade Company se tornaria a Ashanti Goldifield (Boahen, 1975).

5 O nome do relatório decorre do fato de ter sido elaborado sob a liderança de Lloyd Quarshie, um engenheiro de minas ganense (Anin, 1989).

6 A Ghana Chamber of Mines é uma associação que conta com mais de 60 empresas que se relacionam à mineração, como: empresas de contratação de serviços mineiros (aquelas que realizam reparos técnicos em maquinários danificados ou que realizam etapas específicas do processo de extração e processamento do ouro, como levantamentos geológicos e escavação); empresas de consultoria legal e jurídica; empresas de logística 
e transporte; empresas varejistas (que comercializam maquinários e instrumentos necessários ao desenvolvimento da atividade de mineração); bancos comerciais (como o sul-africano Standard Bank), seguradoras, dentre outras. Deve-se ainda levar em consideração a presença de instituições públicas (Minerals Commision, Geological Survey Department, University of Mines and Technology e a Ghana Atomic Energy Commision) no processo de produção de conhecimento científico acerca das condições geológicas e geomorfológicas dos terrenos onde ocorre a exploração mineral.

\section{Referências}

AKABZAA, T.; DARIMANNI, A. Impact of mining sector investment in Ghana: a study of the Tarkwa mining. Draft Report for SAPRI, 2001. Disponível em: <http://www.saprin.org/ghana/research/gha_mining.pdf> Acesso em: 20 dez. 2015.

ANGLOGOLD ASHANTI. Disponível em: < http://www.anglogoldashanti.com> Acesso em: 10 fev. 2016.

ANIN, T. E. Gold in Ghana. Accra; Londres: Selwyin Publishers Ltd., 1989.

BOAHEN, A. Ghana: evolution and change in the nineteenth and twentieth centuries. Londres: Longman, 1975.

CAMPBELL, B. Introduction. In: CAMPBELL, Bonnie (Ed.) Mining in Africa: regulation and development. Nova Iorque: Pluto Press, 2009. p.1-24.

CIA WORLD FACT BOOK. Disponível em: <https://www.cia.gov/library/ publications/the-world-factbook/geos/gh.html> Acesso em: 23 mai. 2018.

DAVIDSON, B. A history of West Africa: 1000-1800. Londres: Longman, 1985.

ENDEAVOUR MINING CORPORATION. Disponível em: <https://www. endeavourmining.com > Acesso em: 10 fev. 2016.

G4S. Disponível em: <http://www.g4s.com> Acesso em: 10 fev. 2016.

GHANA CHAMBER OF MINES; INTERNATIONAL COUNCIL ON MINING AND METALS. Mining in Ghana: What future can we expect? 2015. Disponível em: <http://www.icmm.com/document/9151> Acesso em: 20 dez. 2015.

GHANA MINE WORKERS UNION. Disponível em: <http://www. ghanamineworkersunion.org > Acesso: em 11 fev. 2016.

GOLD FIELDS. Disponível em: <https://www.goldfields.co.za> Acesso em: 10 fev. 2016.

GOLDEN STARS RESOURCES. Disponível em: < http://www.gsr.com> Acesso em: 10 fev. 2016.

GEERTZ, Clifford. The interpretation of cultures. Nova York: Basic Books, 1973. p. 3-30.

GRANT, R. Africa: geographies of change. New York: Oxford University Press, 2015. 
HILSON, G. et al. Chinese participation in Ghana's informal gold mining economy: drivers, implications and clarifications. Journal of Rural Studies, v. 34, p. 292-303, April 2014.

HUTCHFUL, E. Ghana's adjustment experience: the paradox of reform. Oxford: James Currey, 2002.

KINROSS GOLD CORPORATION. Disponível em: <http://www.kinross.com>. Acesso em: 10 fev. 2016.

KPMG GLOBAL MINING INSTITUTE. Ghana, country mining guide. 2014. Disponível em: <https://www.kpmg.com/GH/en/Documents/ghana-miningguide\%202014.pdf >. Acesso em: 10 fev. 2016.

MAMIGONIAN, A. A geografia e a formação social como teoria e como método. In: SEMINÁRIO INTERNACIONAL: O MUNDO DO CIDADÃO, UM CIDADÃO DO MUNDO, 1996, São Paulo. Anais... São Paulo: USP, 1996.

NEWMONT MINING CORPORATION. Disponível em: < http://www.newmont. com>. Acesso em: 10 fev. 2016.

NYAME, F.; GRANT, J. A. The political economy of transitory mining in Ghana: understanding the trajectories, triumphs, and tribulations of artisanal and small-scale operators. The extractive industries and society. v. 1, n. 1, p. 75-85, Mar. 2014.

OEC. Observatory of Economic Complexity. Disponível em: <http://atlas. media.mit.edu/en/>. Acesso em: 4 abr. 2018.

OKOH. Godfried Appiah. Grievance and conflict in Ghana's gold mining industry: The case of Obuasi. Futures, v. 62, Part A, p. 51-57, October 2014.

PERSEUS MINING LIMITED. Disponível em: <http://www.perseusmining. com>. Acesso em: 10 fev. 2016.

PRECIOUS MINERALS MARKETING CORPORATION. Disponível em: < http:// pmmcghana.com> Acesso em: 10 fev. 2016.

SANTOS, K. L. dos. Pontas em circuito: As inserções de Gana na divisão internacional do trabalho contemporânea. 2017. Tese (Doutorado em Geografia Humana) - Faculdade de Filosofia, Letras e Ciências Humanas da Universidade de São Paulo, São Paulo, 2017.

SANTOS, M. Sociedade e espaço: a formação social como teoria e como método. Boletim Paulista de Geografia, São Paulo, n. 54, AGB, p.35-59, 1977.

Kauê Lopes dos Santos - Bacharel e Licenciado em Geografia pela Universidade de São Paulo. Mestre em Habitat pela Faculdade de Arquitetura e Urbanismo da Universidade de São Paulo. Doutor em Geografia Humana pela Faculdade de Filosofia, Letras e Ciências Humanas da Universidade de São Paulo. Atualmente é Pós-doutorando em Geografia pela mesma Universidade. ORCID: https://orcid.org/0000-0001-9996-1079 